\title{
Development of Legal Protection Protocols for Victims of Domestic Violence to Improve the Quality of Life and Reproductive Health of Women During the Covid-19 Pandemic in Medan
}

\author{
Alvi Syahrin ${ }^{1}$; Nur Asiah ${ }^{2}$; D. K. Dewi ${ }^{3}$ \\ ${ }^{1}$ Professor of the Faculty of Law, University of North Sumatra, Medan, Indonesia, 20155 \\ ${ }^{2}$ Lecturer at the Faculty of Nursing, University of North Sumatra, Medan, Indonesia, 20155 \\ ${ }^{3}$ Lecturer at the Faculty of Law, Tjut Nyak Dhien University Medan, North Sumatra, Indonesia
}

\section{*Corresponding Author Email: alviprofdr@usu.ac.id; kesuma240284@gmail.com}

\begin{abstract}
Domestic violence (KDRT) is usually a female victim or wife whose effects include physical pain, mental stress, decreased self-confidence and self-esteem, experiencing feelings of helplessness, post-traumatic stress, depression, and even the desire to commit suicide. Especially during the Covid-19 pandemic this time, there was a lot of domestic violence in Medan. Domestic violence that results in reproductive health problems and ultimately results in sociological disorders. The problem is what is the statutory protocol in implementing legal protection for victims of domestic violence and what is the impact of domestic violence on the reproductive health of victims of domestic violence. Indonesia has a traditional instrument in the form of Law Number 23 of 2004 concerning the Elimination of Domestic Violence (UUPKDRT). Based on Article 4 of UUPKDRT, all forms of domestic violence need to be prevented by punishing the perpetrators with imprisonment and fines. Settlement of domestic violence cases to realize women's rights to obtain healthy reproductive health so as not to experience menstrual disorders, experience premature menopause, experience decreased libido, inability to orgasm or other things that affect the health of the reproductive organs. Domestic violence, which started as a privacy issue, then became a public issue. For this reason, the role of law enforcement officials and their supporting institutions needs to develop a legal protection protocol for victims of domestic violence to improve the quality of life of women, especially in the Medan area.
\end{abstract}

Keywords: COVID-19; Pandemic; Mental Health; PKDRT Law Protocol; Legal Protection; Reproductive Health; Domestic Violence

\section{INTRODUCTION}

Prior to COVID-19, 1 in 3 women globally experienced violence by a partner engaging in intimate and casual relationships. However, the pandemic has overtaken domestic and private partner violence against women, with a growing array of physical, psychological and sexual violence, and violence typologies (e.g., child abuse, parental abuse, pet abuse, femicide, cyberviolence), stalking, and financial information).

One of the strategies often used to understand violence against intimate partners and sexual harassment against women is the motive of family violence or domestic violence, which was developed mainly from the fields of sociology and psychology. "Domestic violence" refers to all forms of violence in the family regardless of the age or sex of the victim or perpetrator. Although their partners often make women, parents, or other family members as victims, the concept of "domestic violence" does not cover various types of violence that women experience outside the home, such as sexual harassment and harassment in the workplace.
In addition, the researchers found that the assumption of gender neutrality in the term "domestic violence" is problematic because it fails to attract that violence in the family is mostly perpetrated by men against women and children. There is a growing international agreement that abuse of women and girls, wherever it occurs, should be "gender-based violence", as it mostly stems from the subordinate status of women in society to that of men.

The official United Nations definition of gender-based violence includes most of the harmful behavior directed at women (wives) because of their gender. Harassment, murder related to marriage, rape in marriage, malnutrition of girls, forced prostitution, female genital mutilation, and sexual abuse of girls. Even when abuse of women by male partners is conceptualized as gender-based violence, the terms used to describe this type of power are inconsistent.

In many parts of the world, the term "domed violence" refers to mistreatment of an intimate female ex or former male partner. In some countries, however, "domestic violence" refers to violence that 
occurs at home, including violence against children and parents. The term "lagging women" emerged in the 1970s to describe women who experience a systematic pattern of domination and physical assault by their male partner. The words "partner abuse", "sexual assault", "intimate partner violence", and "wife abuse" or "wife assault" are generally used interchangeably, although each term is flawed. "Partner abuse" and "intimate partner violence" do not make it explicit that the victim is usually a woman but that the victim could be a boy. We now know that women are attacked more frequently by their partners than men.

The WHO's 2002 report on "Violence and Health" shows the quality of women's health has drastically decreased due to the violence they experience. It is proven that between 40-70 percent of women who die because of homicide, are generally committed by their ex or their partner (WHO, 2002). Studies conducted by WHO in 10 countries show that 15-71 percent of women experience physical or sexual violence by their partners or partners [9].

Until now, data recording of domestic violence cases can be traced from the platform regulated in the Law on the Elimination of Domestic Violence Number 23 of 2004 concerning Domestic Violence (KDRT). The National Commission on Violence against Women or known as Komnas Perempuan in 2014 showed cases of violence against women reached 293,220 cases. of these, about $96 \%$ or 280 . 710 were cases of domestic violence. This data is obtained from Komnas Perempuan 'only' from the Religious Courts which are only recorded as having civil roots. Meanwhile, for victims who experienced domestic violence and were brought to criminal law, it was lower. 74 percent of them were cases of domestic violence (Kalibonso, 2002: p.25). And data from the Women's Crisis Center (WCC) Mitra Perempuan [8] notes that 87 percent of women victims of violence who access their services experience domestic violence, where the most perpetrators of violence are husbands and exhusbands $(82.75 \%)$.

North Sumatra Province, especially Medan City, which is a developing city, is supported by people who have a fairly high rhythm of life, this has an impact on the vulnerability of domestic violence. This shows that out of 100 percent of cases of violence against women in Medan it is very high and the estimates from these data cannot represent the existence of all women who have experienced violence. Because as we know, some women view violence as a disgrace, so they prefer to remain silent with violence rather than expose their domestic problems to general problems.

Why is that? There are several reasons, first, there are still many women (wives) who still have low knowledge of the UUPKDRT which is a legal protection protocol for victims of domestic violence. There are several factors that cause a wife's lack of knowledge and attitudes towards domestic violence, namely age, education and occupation. One example that we often encounter non-physical acts of violence that occur to women such as humiliation, women (wives) who do not understand the humiliation of men (husbands) will be silent and do not understand what they will do to be able to overcome their psychological consequences due to abuse insults from men (husbands). However, if they (wives) understand the insult, then all they know is that the perpetrator (husband) is only subject to criminal sanctions with the article of public defamation, namely Article 310 of the Criminal Code. Meanwhile, humiliation is part of domestic violence because it can psychologically disturb women (wives). From Article 310 of the Criminal Code above, it will be very difficult to ensnare perpetrators of Domestic Violence (KDRT). With the issuance of the UUPKDRT by the government, it gives access to victims to be able to complain about perpetrators of domestic violence with this law.

The second reason is that these women still have economic and psychological dependence on the perpetrator (partner). Economic limitations and the need to be protected and loved by others (partners) are the main causes of victims' reluctance to report perpetrators of domestic violence. Even though the violence that occurred was sometimes classified as serious domestic violence, the victim did not want to act or was imprisoned. They only hope that the perpetrator can change their behavior. From here, it is not uncommon for victims to only undergo criminal proceedings if the violence is really serious and occurs repeatedly. The very patriarchal culture of society that places women in second class makes women victims of domestic violence are also often considered by the community as the cause of violence. Another reason that makes women survive is the fear of being left behind and becoming widows. The status of widows in Indonesian culture is labeled negative and is not ready to accept it. However, the reasons most often encountered are slacking off for the sake of the child, for fear that their child will no longer have a father figure, fear of hurting their children, and all considerations about children. Thus, women as parties who are almost 
always victims of domestic violence experience various burdens that come from outside and themselves. This means that the community or family often blames them and are still very economically and psychologically dependent on perpetrators of domestic violence.

The third reason is that many victims of domestic violence, especially those who experience disturbed reproduction of their health, and instead choose to remain silent due to ignorance or low education. Violence against women can have fatal consequences in the form of death, attempted suicide and contracting HIV / AIDS. In addition, violence against women can also have non-fatal effects such as physical health problems, chronic conditions, and mental disorders, unhealthy behavior, and reproductive health problems. Both fatal and nonfatal effects all reduce women's quality of life [4]. The facts show that 9 out of 10 women victims of domestic violence experience mental health problems, 12 have attempted suicide; and 13.12 percent of them suffer from reproductive health problems.

Therefore, a socialization / extension of the Law on the Elimination of Domestic Violence is absolutely necessary. This law is a government preventive effort so that domestic violence does not happen again. Socialization / counseling on Legal Protection Efforts against Victims of Domestic Violence in the city of Medan, North Sumatra is needed so that people know and understand that currently there is a law that protects it from all forms of violence perpetrated by husbands against wives or wives against husbands. , to children, to biological parents, and to domestic servants. The aim of this activity is to develop a legal protection protocol for victims of domestic violence in the context of preventing and eliminating domestic violence.

Apart from that, the role of government, law enforcers, educational institutions, health institutions and social institutions is highly expected. Likewise, the role of the Medan Child and Women's Protection Study Center together with researchers consisting of lecturers in providing information services related to PKDRT regulations aimed at women victims of violence in Medan which include information, consultation, psychological, legal, mentoring and advocacy services as well as health houses and safe houses. (shelter). In addition to providing advocacy services and information related to domestic violence, they also create applications that make it easier for everyone to report criminal cases of domestic violence through an android application. The goal is that people who want to see and report an incident of domestic violence no longer have difficulty finding media or forums as a forum for legal protection. Also, the role of the mass media through public service advertisements regarding this regulation is very influential.

Looking at the series of facts above, cases of domestic violence are an iceberg phenomenon recently and have recently begun to emerge to the surface and from time to time the number of social cases has increased and it is not an exaggeration to say that domestic violence is also a part of public health problems that need get attention. So we also need a study on women's health and domestic violence towards women, recommending and asking for concrete steps from policy makers and the public health sector to increase the health and humanitarian budget, including including violence prevention programs in the scope of social activities [3].

In this study, the focus of research is legal protection for victims of domestic violence, especially women in building good governance during the Covid-19 pandemic related to legal protection protocols. This study aims to develop the rules of Law Number 23 of 2004 concerning the Elimination of Domestic Violence which can provide legal protection and minimize, eliminate every act of violence in the household, especially against women to improve the quality of life and women's reproductive health. during the Covid-19 Pandemic in Medan.

\section{METHODS}

This research is a normative legal research based on literature and field studies on the formation of a criminal law system related to the law on the elimination of domestic violence using descriptive analysis (Soekanto, Soerjono, 2007: p.50) regarding the nature of the research. This research was conducted in the city of Medan. With the consideration that at that location there were several cases of domestic violence (KDRT) committed by the husband against his wife.

The implementation of this research was approximately two weeks, until the data desired by the researcher were fulfilled perfectly. In determining the information is done using purposive sampling technique, namely the selection of informants is determined by the researcher according to the needs. With the consideration that the selected informants are informants who can provide accurate information to researchers, as argued by Arikunto (2002) argues that purposive sampling is a method based on considerations that predetermined informants have competence, 
sufficient knowledge and credibility. to answer the questions in the interview.

The types of data in this study are qualitative data and quantitative data. Which is where qualitative data is presented in narrative form to describe women (wives) who have experienced domestic violence and qualitative data, namely data based on information from the object under study. While the type of research uses qualitative descriptions where the researcher describes or constructs in-depth interviews with the research subjects. With qualitative data we can follow and understand the flow of events chronologically, assess cause within the scope of local people, and obtain many useful explanations.

The qualitative data obtained is based on information material or findings from the object under study regarding violence against women (wives) in households in the city of Medan, especially during the Covid-19 Pandemic who was very vulnerable in the implementation of domestic violence. Meanwhile, quantitative data is a type of research that involves taking statistical data so that calculations and interpretations can be carried out which can be presented in the form of graphs, diagrams, tables, and hypothesis testing.

Primary data is data obtained directly from the perpetrators and victims of male violence (husband) interviews and observations. Secondary data is data obtained through library research to obtain a theoretical basis, namely reading various literatures or existing books with the object of research. The data technique in this study was carried out by conducting data directly in the field to obtain accurate data, and techniques and data use were the most strategic steps in research, because the main purpose of the study was to get data. The method used is library study, to obtain a theoretical basis, namely by reading various literature or books written by experts, who provide opinions, reasoning, theories or ideas relevant to research problems. Field research, namely research carried out directly on the object of field research.

This research includes observation, namely observation or careful observation of the research area to obtain a picture of the situation of society in general and women (wives) who have experienced domestic violence (KDRT) so that it facilitates the authors of this study. Interview, namely by holding free and in-depth questions and answers to informants using new systematic interviews, so as to provide clear information about domestic violence (KDRT) that reports women (wives) in Medan. The data analysis technique uses the steps used to answer the problem formulation in this study. The goal is to get the results of the research. The data obtained from field research and data from the literature are then analyzed descriptively qualitatively, namely an analysis that describes social phenomena, namely regarding domestic violence (KDRT) which is suitable for women (wives) in Medan City.

Retrieval of data that is specific and related to the problem being discussed or discussed and described in a logical and systematic sentence to answer the problem formulation in this study. Thus the truth will be scientifically accounted for based on the data obtained.

\section{RESULT AND DISCUSSION}

Low Knowledge of Women (Wives) About Domestic Violence)

Before counseling was given, the respondents' knowledge, namely women (wives), was still low about domestic violence because respondents did not get information about the definition, types, factors, and laws that govern domestic violence. One of them is non-physical acts that can occur to a woman (wife) committed by the man (husband), for which there is a criminal sanction, namely humiliation in public (Article 310 of the Criminal Code), women (wives) who do not understand that this is a crime. is one of the acts of violence in the household so he considers it an Umrah / ordinary thing. However, many people around him think that it is a general criminal act related to the Criminal Code. In fact, basically Article 310 of the Criminal Code is not specifically for women (wives) who experience domestic violence, but this article is for the public which is ultimately difficult for the woman (wife) to bring to the surface themselves. Therefore, the researcher provided an intervention in the form of counseling that provided information about domestic violence so as to increase respondents' knowledge about domestic violence. This is in accordance with the theory put forward by Notoatmodjo (2014) that knowledge is the result of "knowing", and this occurs after a person senses through the five senses of sight, hearing, smell, and the senses to know. Part of human knowledge is obtained through the eyes and ears. Knowledge or cognitive is a very important domain for shaping one's actions. In addition, a person can also obtain self-knowledge from others through hearing or information, sight and feeling, either directly or indirectly through print and electronic media. Knowledge is influenced by several factors, namely age, education, occupation, experience, culture, and information. The assumption of researchers about knowledge of 
domestic violence is good, but there are still some that are lacking, this can be seen from the results of the research that has been done, namely there are still respondents who have less knowledge. In this case it can be seen that a person's knowledge varies because it is influenced by several factors, namely age, education, occupation, experience, culture, and information. The more dominant factor is education. Respondents' education tends to be low, so that some respondents find it difficult to accept the knowledge they get, then because of low education, respondents tend to be unable to develop themselves.

Then after processing research data on the knowledge and attitudes of wives after being given counseling on domestic violence in Medan in the August 2020 period, the results showed that there was an increase in the attitude of respondents before and after counseling about domestic violence. Prior to counseling, respondents still fostered a lower position for women than men, so that respondents tended to be afraid and silent when experiencing domestic violence. Lack of information regarding the process of reporting cases of domestic violence was also the reason respondents were unable to report acts of domestic violence. Then the researchers provided counseling with electronic media in the form of an android application containing an invitation to respondents not to be silent when experiencing domestic violence. This application can shape the respondent's attitude to be positive. Furthermore, the researcher explained the process of reporting cases of domestic violence, namely first through the legal route of the Women and Children Service Unit (UPPA) at the nearest Polres. In addition, victims or their families can also ask volunteer assistance to accompany the victims to report to the police. After that the victim will experience psychological recovery accompanied by psychological-based institutions until recovery. In accordance with the theory of attitude formation put forward by Saifuddin Azwar (2007) that attitudes can be formed and influenced by mass media as a means of communication, various forms of mass media such as television, radio, mobile phones, newspapers, posters, magazines, books, etc. -other. Conversely, has a major influence on attitudes through the formation of one's opinions and beliefs. In delivering information as its main task, the mass media also carries messages containing suggestions that can direct someone's opinion. The existence of new information about something provides a new cognitive basis for forming attitudes towards it. The suggestive messages conveyed by this information, if strong enough, will provide an affective basis for judging something so that certain attitudes are formed (Saifuddin Azwar M., 2016). The assumption of researchers about attitudes towards domestic violence is good but there are still some that are lacking, this can be seen from the results of the research that has been done, namely that there are still some respondents who have less attitudes towards domestic violence. In this case, it cannot be denied that a person's attitude is influenced by several factors, namely personal experience, the influence of other people who are considered important, culture, mass media, educational and religious institutions, and emotional factors (Retno Kusuma Wati, 2014). The more dominant factor that occurs in respondents who is the reason for remaining negative after intervention is culture. It is not easy to change the culture that has long been applied in one's life. The culture that occurs is that the position of women is lower than that of men, so that respondents are afraid and silent when experiencing domestic violence.

\subsection{Legal Protection for Victims of Domestic Violence and Law Enforcement Efforts}

The Law on the Elimination of Domestic Violence contains various reforms and breakthroughs in the protection of Human Rights (HAM) which prioritizes prevention (preventive) of domestic violence, acts of a punitive nature (repressive) and broadens the concept of domestic violence, which does not only include violence. psychic, physical and sexual realms. However, acts that include 'abandoning the household as an act of violence that can be punished. The Law on the Elimination of Domestic Violence is a law that addresses specific issues, so it contains special lex content (www.lbhapik.com, 2010). Consists of:

a. A corrective element to the perpetrator. The Law on the Elimination of Domestic Violence regulates alternative sanctions from the KUHP which only regulates imprisonment and fines, namely in the form of social work and intervention programs imposed on perpetrators. This is intended to prevent the perpetrator from committing violence again;

b. Preventive element to society. The existence of the Law on the Elimination of Domestic Violence is intended to prevent acts of violence that occur in the household sphere, because so far, the issue of domestic violence is considered a private problem so that violence that occurs is not easy to intervene; 
c. Protective element for victims. The Law on the Elimination of Domestic Violence contains articles that provide protection for victims of violence that occur in domestic relations, especially against subordinated parties (vulnerable groups).

Forms of domestic violence have different degrees of violence, this can be seen from the various impacts of violence on victims, so different sanctions must be applied. Prison sentences as stipulated and regulated in the Criminal Code often create a dilemma for victims, because of the economic and social dependence of the perpetrators, so that in the end victims tend not to report the violent crimes they have experienced.

Victims of violence can come from various backgrounds of age, education, socioeconomic level, religion, and ethnicity (Kristi Poerwandari, 2000). What is meant by victims according to Law Number 23 of 2004 concerning the Elimination of Domestic Violence are people who experience violence and / or threats of violence in the household environment (PBB in Rena Yulia N., 2004: p.320).

Arif Gosita provides an understanding of victims, namely those who suffer both physically and spiritually as a result of the actions of others who seek to fulfill their own or other people's interests that are contrary to the interests and rights of those who suffer [1].

So far, the Criminal Code and the Criminal Procedure Code have proven unable to provide protection for victims of domestic violence (KDRT). Because these two regulations are still very general, they do not consider the difficulties of victims to access legal protection, especially because of their gender. The Criminal Code and the Criminal Procedure Code do not take into account the patriarchal and feudal cultural contexts as well as the differences in class / social status which lead to imbalances in social relations, especially in domestic relations. These rules assume everyone is equally capable and empowered to obtain legal justice.

In the Law on the Elimination of Domestic Violence, it regulates the rights of victims, namely in Article 10, among which are protection, health services, special handling and assistance by social workers, according to Arif Gosita [1] victims have rights- the following rights:

a. Get Compensation for His Suffering;

b. Refusing Restitution for the Actor's Interest (Do not want to be given restitution because you don't need it);

c. Get restitution / compensation for his heirs if the victim dies because of this action; d. Receive Development and Rehabilitation;

e. Got His Ownership Rights Back;

f. Get protection from the threat of the perpetrator when reporting and becoming a witness;

g. Getting Help from Legal Counsel H. Using Legal Remedies.

With the existence of this article which contains the rights of victims, it is hoped that victims of domestic violence will receive protection from the state and / or society so that they do not cause prolonged traumatic impacts. In accordance with the preamble to the Law on the Elimination of Domestic Violence, victims of domestic violence, most of whom are women, must receive protection from the state and / or society in order to avoid and be free from violence or threats of violence, torture, or treatment that degrading the degree and dignity of humanity.

In addition to regulating the rights of victims, the Law on the Elimination of Domestic Violence also regulates the protection of victims of violence provided by the police in collaboration with health workers, social workers, volunteer companions, and / or spiritual mentors to assist victims (Article 17). Regarding the procedure for reporting incidents of domestic violence, victims of domestic violence can report domestic violence directly to the police, either at the place where the victim is at or at the scene of the case or can also give power to their family or other people to report the violence they have experienced.

After a criminal act of domestic violence is reported to the authorities, within $1 \times 24$ (one time twenty four) hours from knowing or receiving a report on domestic violence, the police are obliged to immediately provide temporary protection to the victim. This protection is given no later than 7 days after the victim is received or handled and the police are obliged to request a protection order from the court.

The chairman of the court, within a period of 7 (seven) days from the receipt of the application, is obliged to issue a decree containing an order of protection for the victim and other family members, unless there is a good reason. Applications for a protection warrant can be submitted by:
a. victim or victim's family;
b. friend of the victim;
c. police;
d. companion volunteer; or
e. spiritual guide.
Applications for protection can be submitted either orally or in writing. A protection order issued by the head of the District Court can be given for a 
maximum period of 1 (one) year and can be extended upon court's decision. Thus regarding the protection of victims of domestic violence, normatively it has fulfilled, but it needs further implementation of these provisions in the form of policies and actions. Regarding the government's efforts to prevent domestic violence, it is regulated in Article 12 of the Law on the Elimination of Domestic Violence, namely:

a. formulating policies on the elimination of violence in household;

b. organizing communication, information and education about domestic violence;

c. organize outreach and advocacy on domestic violence; and

d. conduct gender sensitive education and training and domestic violence issues and establish standards and accreditation of gender sensitive services.

Prevention efforts above are expected to provide broader knowledge to the community about household life that is sakinah mawaddah warahmah and does not discriminate against parties considered subordinate so as to prevent violence in the household. However, if domestic violence has occurred, the government and local governments in accordance with their respective functions and duties can provide services to victims by making the following efforts:

a. provision of special service rooms at the police station;

b. provision of apparatus, health workers, social workers, and spiritual guides;

c. Creation and development of service program cooperation systems and programs involving parties that are easily accessible to victims; and

d. provide protection for companions, witnesses, families and friends of victims.

The Law on the Elimination of Domestic Violence also regulates criminal sanctions for perpetrators of domestic violence, criminal sanctions in the form of criminals, fines, and additional crimes in the form of:

a. perpetrators of crimes whose aim is to distance the perpetrator from the victim within a certain distance and time, as well as certain rights of the perpetrator;

b. determination of the perpetrator to follow a counseling program under the supervision of a certain institution.

However, in the Law on the Elimination of Domestic Violence an alternative system of sanctions is formulated, perpetrators of domestic violence can be subject to criminal or criminal fines. Thus for its implementation it will provide injustice to victims of domestic violence themselves, with the existence of alternative sanctions, perpetrators of domestic violence can choose to pay fines to carry out imprisonment.

Furthermore, efforts to prevent and eradicate domestic violence as law enforcement of the Law on the Elimination of Domestic Violence must be pursued jointly between the government and the community as well as the victims of violence themselves. This is because domestic violence, both physical, psychological and sexual, is an offense for complaints [2] so that good cooperation between all parties is needed.

\subsection{Impact of Violence on Health}

Health based on ICPD (1994) is a state of complete physical, mental and social well-being, not alone free from disease or disability in all matters relating to the system being equipped, as well as its functions and processes. with the impact of violence on sexual life and women, research conducted by Rance (1994) cited by Heise, Moore and Toubia (1995) violence and male domination can limit and shape sexual and women's lives. In addition, men are also influential in making decisions about contraceptives used by their partners. Furthermore, what was done in Norway by Schei and Bakketeig (1989) cited by Heise, Moore and Toubia (1995) also stated that women who live with partners who like to commit violence show more severe gynecological problems with those who live with a partner. normal partner; even these gynecological problems can persist in continuous pain.

Violence against wives needs to be revealed to find alternative empowerment for wives to avoid acts of violence that should not occur in order to realize women's rights to obtain healthy reproductive health. Women reproductive health is disturbed if at the time they are not pregnant they experience menstrual disorders such as menorrhagia, hypomenorrhagia or metrorhagia. even women can experience menopause earlier, can experience decreased libido, inability to get orgasm, due to the violence they experienced. Worldwide, one in four pregnant women experience physical and sexual violence by their partners. During pregnancy, there can be miscarriage / abortion, immature labor and the baby dies in the womb. During childbirth, women will experience labor complications such as loss of uterine contractions, prolonged labor, labor with instruments and even surgery.

The result of pregnancy can give birth to a baby with LBW, mentally retarded, a baby born with 
physical defects or a stillborn baby. Other impacts that also affect the health of the wife's reproductive organs in the household include changes in thinking patterns, emotions and the family economy. Impact on the wife's mindset. Violence also affects the victim's way of thinking, for example, being unable to think clearly because he is always afraid, tends to be suspicious (paranoid), has difficulty making decisions, cannot believe what happened. Wives who are victims of violence have physical and mental health problems twice as large as those who are not victims including mental stress, physical disorders, dizziness, menstrual pain, infection with infectious diseases. Impact on the family economy. Another impact of violence, although not always economic problems, affects not only women who do not work but also women who earn a living. Such as sudden disconnection of economic access, loss of control of the household economy, unexpected costs for housing, relocation, treatment and therapy and court fees. Impact on wife's emotional status. The wife can experience depression, abuse / use of certain substances (drugs and alcohol), anxiety, attempted suicide, post-traumatic conditions and low self-esteem. The struggle to eliminate domestic violence starts from the fact that many cases of domestic violence that occur with the majority of victims are women and children. This is based on a number of findings by the National Commission on Violence against Women (Komnas Perempuan) from various service providers for victims of violence. From a legal standpoint, the absence of firm sanctions and deterring perpetrators has perpetuated violence or crime in society. Such as the perpetrator of rape who was lightly punished, the perpetrator of adultery who was even ignored, and others. From a socio-cultural perspective, a hedonistic lifestyle that gives birth to permissive behavior, freedom of behavior and free sex, has fostered sexual deviant behavior such as homosexuality, lesbianism and sex with violence.

From an educational point of view, the symptoms of ignorance have triggered a lack of understanding by some people about the effects of violence and how they should behave politely. This is due to the government's low awareness in handling education, so that the capitalization of education only favors rich people. Ignorance is born systematically in society. and deterioration of people's thinking, so that behavior is at a very low degree. For this problem, a comprehensive application of law by the state is needed. Otherwise there will be inequality. For example, it is difficult to eliminate prostitution, if economic factors are not corrected. Because, not a few people prostitute because of economic problems. Violence in the household, if only seen from the wife having to serve her husband, must be lame. Whereas in Islam, the husband is obliged to do good to his wife.

Violence by the husband, such as physically hurting him, can be subject to diyat sanctions. This is where it is important to uphold a firm and comprehensive law. According to article 11 of the PKDRT Law, the government is responsible for efforts to prevent domestic violence and according to Article 12 paragraph (1) organizing advocacy and socialization on domestic violence is also the government's responsibility. However, in fact, the socialization and advocacy of domestic violence is still minimal. There are still many people who do not know or even understand the PKDRT Law, even among law enforcement officials there are still various perceptions. In addition, adequate socialization is needed for the wider community, especially for those who have the potential to commit domestic violence, as a preventive measure.

For parties who may become victims of domestic violence, socialization is necessary, so that if domestic violence occurs, they can improve their fate because they already know their rights. The PKDRT Law needs to be revised in parts that are ambiguous and require additional types of violence, such as economic violence and social violence. In addition, it is necessary to harmonize laws and regulations that are not in line with the breath of gender equality, among others by revising the Marriage Law, so that statutory regulations can support each other and do not conflict with each other, so that the PKDRT Law can be felt its effectiveness. Law enforcement of the PKDRT Law cannot be separated from law enforcement in general. If the state is unable to create the rule of law, the protection regulated in the PKDRT Law will only be in the form of law in book (theory), while in law in action (practice) it will be difficult to materialize. Therefore, the rule of law must be upheld.

Things that can be given to help women from acts of domestic violence are:

1. To recommend shelters such as crisis centers, shelters and one stop crisis centers;

2. Provide psychological assistance and physical treatment services for victims. Here the nurse can play a role with a focus on increasing the self-esteem of the victim, facilitating the expression of victim's feelings, and enhancing an enabling social environment. Midwives 
play an important role in helping victims of violence, including through primary prevention efforts consisting of family counseling, modification of the sociocultural environment and spiritual guidance, secondary prevention efforts with the application of health according to the problems faced by clients, and tertiary prevention through training / education, formation and processes. groups and rehabilitation services;

3. Providing legal assistance in judicial proceedings.

4. Train cadres (NGOs) to be able to assist victims of violence.

5. Conduct training on the protection of victims of domestic violence as a provision for nurses to assist victims (Emi Sutrisminah, 2004:p.8).

\section{CONCLUSION}

In conclusion, the following answers can be given to the problem regarding narrative conclusions about the legal protection protocol for victims of domestic violence related to the reproductive health of women (wives) in Medan:

1) The effectiveness of the wife's attitude before and after counseling on domestic violence in Medan City is related to the knowledge of Domestic Violence, both the protocol for reporting cases of domestic violence which aim as a legal protection protocol for victims of domestic violence, especially women;

2) Legal protection for victims of domestic violence has been normatively fulfilled in Law Number 23 of 2004 concerning the Elimination of Domestic Violence, but it needs further implementation of these provisions in the form of policies and actions. This law is expected to provide legal protection for victims of domestic violence and restore the rights of victims of domestic violence, especially for women with the aim of improving the quality of life and reproduction of women in the city of Medan;

3) Domestic violence is a type of crime that lacks attention and scope of criminal law. Forms of violence can be in the form of physical, psychological, sexual, and verbal abuse as well as household neglect. Factors that encourage violence against wives in the household are defense of male power, discrimination and economic restrictions, the burden of child care, women as children, and male criminal justice orientation. The impact of violence against wives on reproductive health can affect the mother's psychology so that there are disturbances during pregnancy and childbirth, as well as after childbirth and the baby is born. What must be done is to psychologically support the victim, provide assistance, provide physical care for the victim and recommend a crisis women center. The phenomenon of the iceberg of domestic violence began to unfold after the enactment of the 2004 KDRT law, where domestic violence, which was previously a matter of privacy, has become a public problem, marked by domestic violence case reports are increasing every year and perpetrators are subject to criminal penalties even though Indonesian culture is currently dominated by men.

\section{REFERENCES}

[1] Arif Gosita, The Problem of Crime Victims, Akademika Pressindo, Jakarta, 1993;

[2] Ali, Chidir, Criminal Law Response Bandung: Armico, 1985;

[3] Awaliyah, Ayu Sofhatul. Serious Impact of Domestic Violence on Public Health. MOH, 2011;

[4] Heise L.L., et al., Ending Violence against Women, Population Reports, Baltimore John's Hopkins University, 1994;

[5] Kusuma, H. (2011). The relationship between depression and family support with the quality of life of HIV / AIDS patients who are undergoing treatment at Cipto Mangunkusumo Hospital. Depok: Postgraduate Program, Faculty of Nursing, Specialization in Nursing, Medical Surgery, University of Indonesia;

[6] Kusumawati, M. (2013). The Effectiveness of Cognitive Behavioral Therapy to Increase Self-Acceptance of HIV-Infected IDUs (Injection Drug Users). Independent Psychology;

[7] Rita Serena Kolibonso, The Crime Is Called Domestic Violence, Indonesian Litigation Journal, 2002;

[8] Tamtiari, Wini. Awig-Awig, Protecting Women from Domestic Violence. Yogyakarta: Collaboration between UGM Population 
Research Center and Ford Foundation, 2005;

[9] WHO. 2002. The World Health Report-Reducing Risks, Promoting Healthy Life. Geneva: World Health Organization. Downloaded from

www.who.int/whr/2002/en/whr02_en.pdf 21 November 2020; 